\title{
THE EFFECT OF POLY(N-HYDROXYMETHYL ACRYLAMIDE) CHAIN LENGTH IN POLY(N-VINYL PYRROLIDONE)-BLOCK-POLY(N-HYDROXYMETHYL ACRYLAMIDE) ON ITS SENSITIVITY TO pH
}

\author{
N. M. Nizardo ${ }^{\bowtie}$ and T. P. Tania \\ Department of Chemistry, Faculty of Mathematics and Natural Sciences, \\ Universitas Indonesia, Depok, 16424, Indonesia \\ ${ }^{\square}$ Corresponding Author: noverra.mardhatillah@sci.ui.ac.id
}

\begin{abstract}
The synthesis of $\mathrm{pH}$-sensitive poly(N-vinyl pyrrolidone)-block-poly(N-hydroxymethyl acrylamide)s (PNVP-bPNMA) was carried out using atom transfer radical polymerization by varying the amount of N-hydroxymethyl acrylamide to study its effect on $\mathrm{pH}$. The success of polymerization was characterized using FT-IR and ${ }^{1} \mathrm{H}-\mathrm{NMR}$. The investigation of block copolymers sensitivity to $\mathrm{pH}$ was performed by observing the changes in particle sizes of copolymers at various $\mathrm{pH}$. Particle sizes of PNVP-b-PNMA were affected by the $\mathrm{pH}$, in which they became smaller $(275.43-548.70 \mathrm{~nm})$ at $\mathrm{pH} 9$ and 12 than that in $\mathrm{pH} \mathrm{3,5}$, and $7(394.86-694.56 \mathrm{~nm})$. In addition, particle sizes increased along with the increasing monomer composition of N-hydroxymethyl acrylamide.

Keywords: $\mathrm{pH}$-sensitive polymer, N-hydroxymethyl acrylamide, N-vinyl pyrrolidone, Block Copolymers, Particle Sizes.
\end{abstract}

RASĀYAN J. Chem., Vol. 14, No.4, 2021

\section{INTRODUCTION}

Stimuli-sensitive polymers are polymers that can give responses to environmental changes, which have been known for a long time yet are still under development to study its properties and characteristics with various synthesis methods and techniques. ${ }^{1}$ There are many types of stimuli-sensitive polymers, two of the most interesting types are temperature-sensitive polymer and $\mathrm{pH}$-sensitive polymer. Some polymers can respond to the change of temperature by changing their physical properties and interacting with other molecules. Saxena and Bhatt studied interactions between poly(vinyl alcohol) (PVA) in an aqueous solution by investigating its ultrasonic speed, density, and viscosity. Its physical properties changed towards temperature because of interactions between PVA and water. ${ }^{2}$

$\mathrm{pH}$-sensitive polymers can respond to the change of $\mathrm{pH}$ due to the presence of acidic functional groups, i.e., carboxylic or basic, i.e., amines, in their side chains. Much research about $\mathrm{pH}$-sensitive polymers and their applications has been conducted. Wikantyasning et al. reported the incorporation of gold nanoparticles on agarose hydrogel, which was crosslinked by a $\mathrm{pH}$-sensitive polymer of poly(acrylic acid). As a response to $\mathrm{pH}$ change, this hydrogel nanocomposite had peculiar swelling/deswelling properties response to $\mathrm{pH}$, and thus, it is promising to be used as a nanosensor. ${ }^{3}$ Darjito et al. prepared chitosan-silica by sol-gel method and studied the adsorption of metal ions $\left(\mathrm{Mn}^{2+}, \mathrm{Cu}^{2+}, \mathrm{Zn}^{2+}\right)$ in different $\mathrm{pH}$ solutions. It was found that there was a rise in the adsorption ability of all ions, which is more likely due to the repulsion of the positive charges between the metal ions and the adsorbent. The adsorbent, in particular chitosan, experienced protonation at low $\mathrm{pH}$ resulting in a positive charge in its amine groups. ${ }^{4}$

Another example of a $\mathrm{pH}$-sensitive polymer is poly(N-hydroxymethyl acrylamide) (PNMA), and not many researchers have been investigated its sensitivity to $\mathrm{pH}^{5-7}$ The monomer, $\mathrm{N}$-hydroxymethyl acrylamide (NMA) can be copolymerized with N-vinyl pyrrolidone (NVP), which polymer has been known for its advantages, such as non-toxic, biocompatible, has good affinity to hydrophilic or hydrophobic substances, etc. ${ }^{8}$ Because of its advantages, poly(N-vinyl pyrrolidone) (PNVP) has been applied to various applications. For example, poly(N-vinyl pyrrolidone)-block-polycaprolactone micelles for nanocarriers of anti-TB drugs $^{9}$, metal retention in various $\mathrm{pH} .{ }^{10}$

Rasayan J. Chem., 14(4), 2671-2676(2021) 
To our knowledge, not many studies have been reported regarding the synthesis of PNMA based block copolymers and their $\mathrm{pH}$ sensitivity. We herein present the attempt to synthesize PNVP-b-PNMA using the macroinitiator approach of ATRP with PNVP as the first block and PNMA as the second block by varying the amount of NMA to investigate its effect on $\mathrm{pH}$ sensitivity. The functional groups in copolymers were characterized by FT-IR and the structure of the copolymers was characterized by ${ }^{1} \mathrm{H}-\mathrm{NMR}$. Furthermore, the sensitivity of the copolymers towards $\mathrm{pH}$ was investigated using a particle size analyzer (PSA) in various $\mathrm{pH}$.

\section{Material and Methods}

\section{EXPERIMENTAL}

NVP (Aldrich, 99\%), NMA, ethyl $\alpha$-bromoisobutyrate (EBiB), copper (I) bromide (CuBr, Aldrich, 98\%), 2,2'-bipyridine (bpy, Merck, 99\%), dichloromethane (DCM, Aldrich, 99\%), chloroform (Aldrich, 99\%) and diethyl ether (Aldrich, 99\%) were used as received. The $\mathrm{pH}$ solutions were made from $\mathrm{pH} 5$ and $\mathrm{pH} 7$ phosphate buffer of potassium dihydrogen phosphate and dipotassium hydrogen phosphate. Then, the



\section{Synthesis of PNVP-Br Macroinitiator}

The synthesis method was adapted from others. ${ }^{911-14}$ First, the solvent $\left(20 \mathrm{~mL} \mathrm{H}_{2} \mathrm{O}\right)$ was purged with nitrogen. Then, $\mathrm{CuBr}(1.40 \mathrm{mmol})$ and bpy $(1.40 \mathrm{mmol})$ were added to the solvent and stirred. NVP (70.00 $\mathrm{mmol})$ was then added into the mixture and purged with nitrogen. EBiB $(1.40 \mathrm{mmol})$, was added to the mixture and the polymerization was allowed to proceed for $12 \mathrm{~h}$ at $70^{\circ} \mathrm{C}$. After $12 \mathrm{~h}$, the mixture was exposed to air to stop the polymerization. Purification was done by passing the polymer solution through the alumina column, followed by precipitation in diethyl ether. The obtaining polymer was dried in an oven at $60^{\circ} \mathrm{C}$. As a reference, PNMA was synthesized using a similar procedure.

\section{Synthesis of PNVP-b-PNMA}

PNVP-b-PNMAs were synthesized by using PNVP-Br as a macroinitiator. First, the solvent was purged with nitrogen. After that, $\mathrm{CuBr}$ and bpy were added to the solvent and stirred. Various amount of NMA was added into the mixture and was purged with nitrogen. Then, the macroinitiator PNVP-Br was added to the mixture. The polymerization was carried out at $70^{\circ} \mathrm{C}$ for $6 \mathrm{~h}$. The mixture was exposed to air to stop the polymerization. Purification was conducted by passing the polymer solution through alumina followed by precipitation in diethyl ether. Finally, the polymers were dried in an oven at $60^{\circ} \mathrm{C}$. The synthesis of PNVPb-PNMA method was adapted from others., ${ }^{9}$ 13-14

\section{Characterization Method}

Functional groups of the products were characterized using Shimadzu Fourier Transform-Infrared Spectroscopy (FT-IR) with $\mathrm{KBr}$ at $400 \mathrm{~cm}^{-1}-4000 \mathrm{~cm}^{-1}$. The structure and repeating units (ru) of the products were characterized using ${ }^{1} \mathrm{H}-\mathrm{NMR}$, which were recorded using Bruker-Avance $500 \mathrm{MHz}$ Nuclear Magnetic Resonance in $\mathrm{D}_{2} \mathrm{O}$ as the solvent. The number average molar masses $\left(\mathrm{M}_{\mathrm{n}}\right)$ of the products were calculated from its repeating unit using end group analysis as in eqn.-1.

$$
\mathrm{M}_{\mathrm{n}}=\mathrm{Mr}_{\text {end group }}+\left(\mathrm{Mr}_{\text {ru macroinitiator }} \times \text { ru macroinitiator }\right)+\left(\mathrm{Mr}_{\text {ru second block }} \times \text { ru second block }\right)
$$

The particle sizes were characterized using Horiba-Sz 100Sz particle size analyzer in $\mathrm{pH}$ 3, 5, 7, 9, and 12 at room temperature.

\section{RESULTS AND DISCUSSION \\ Molecular Structure Analysis of PNVP-Br Macroinitiator and PNVP-b-PNMA}

The PNVP-Br macroinitiator synthesized to act as the first block and the second block would be formed by chain extension of this macroinitiator. The FT-IR spectrum of PNVP-Br is shown in Fig.-1, which shows that vinyl peak does not appear. This concludes that the polymer was formed. In comparison with FT-IR spectrum of PNVP that previously had been characterized by other researchers, PNVP-Br in this research gave similar peak positions. ${ }^{15-16}$ Nonetheless, the existence of a hydroxy peak might be caused by the presence of water in the PNVP-Br spectrum. ${ }^{16}$ 
RASĀYAN J. Chem.

Vol. 14 | No. 4 |2671-2676| October- December | 2021

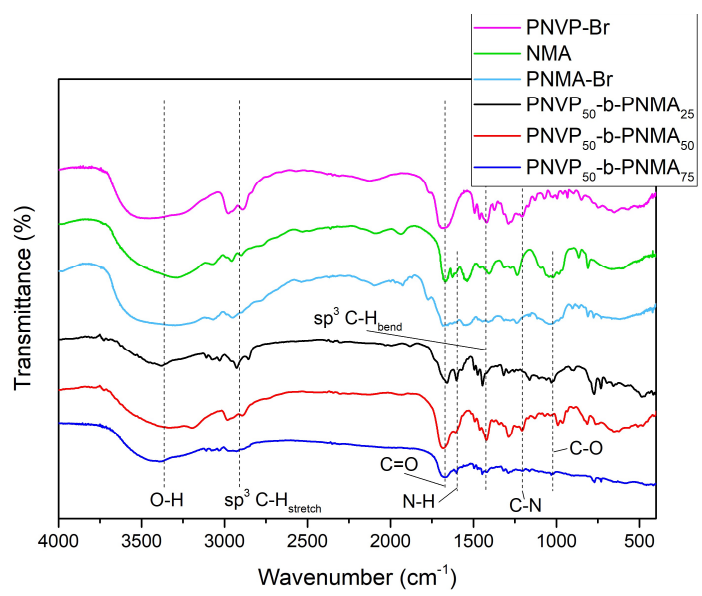

Fig.-1: FT-IR Spectra of PNVP-Br, NMA, PNMA-Br and PNVP-b-PNMA

PNVP-Br was used as a macroinitiator and acted as the first block in PNVP-b-PNMA, while the second block was formed by varying the amount of NMA. Figure-1 shows that PNVP-b-PNMA has the same functional groups in PNMA-Br, that is, N-H and C-O functional groups. Since in FT-IR spectrum of PNVP$\mathrm{Br}$ does not have those functional groups, suggesting that NMA was incorporated into PNVP. Moreover, there are no clear signs of vinyl peaks and these FTIR spectra of PNVP-b-PNMAs gave similar peak positions to FT-IR spectrum of PNVP-co-PNMA that prepared by Marambio et al. ${ }^{10}$

The ${ }^{1} \mathrm{H}-\mathrm{NMR}$ spectrum and the chemical structure of PNVP-Br are shown in Fig.-2(a). It shows that the signals were similar to the ${ }^{1} \mathrm{H}-\mathrm{NMR}$ spectrum of PNVP-Br synthesized by Haaf et al. and Luan et al. ${ }^{17-18}$

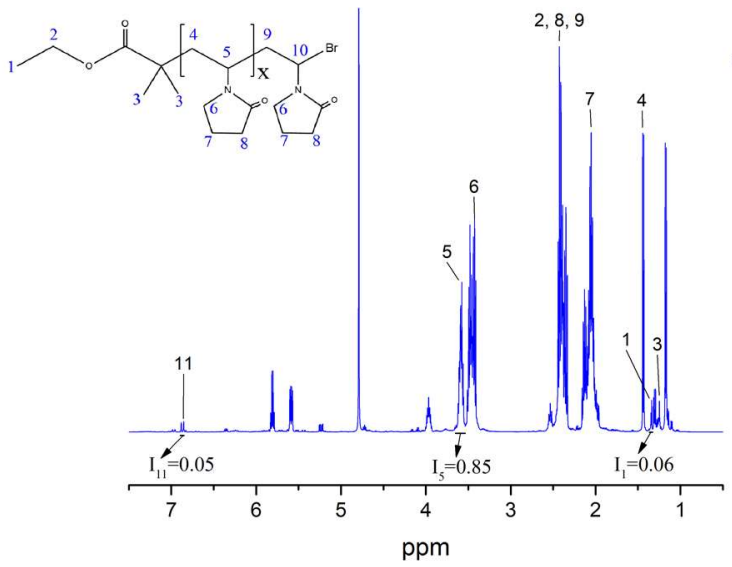

(a)

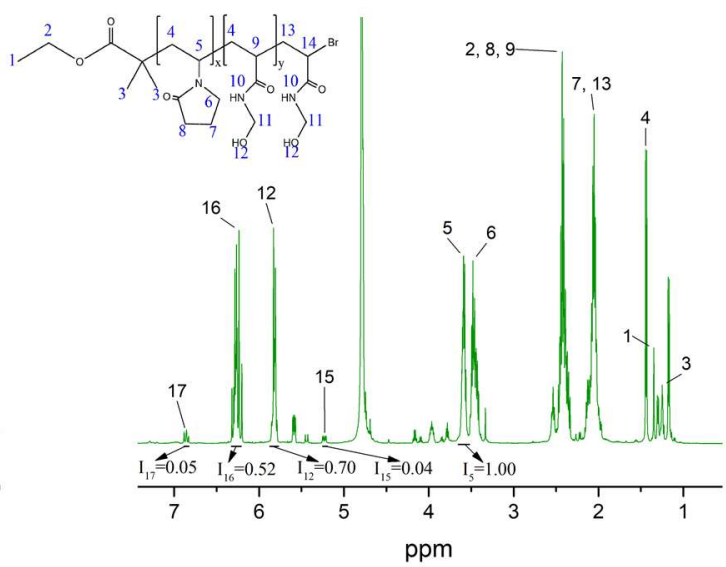

(b)

Fig.-2: ${ }^{1} \mathrm{H}-\mathrm{NMR}$ spectra of (a) PNVP-Br; and (b) PNVP $_{50}$-b-PNMA 75

The repeating unit of PNVP-Br was obtained by comparing the integration of the protons at repeating unit $\left(\mathrm{I}_{5}\right)$ to the integration of end group $\left(\mathrm{I}_{1}\right)$, which come to 40 repeating units, and, thus, number average molar mass $\left(\mathrm{M}_{\mathrm{n}}\right)$ of PNVP-Br is $4155 \mathrm{~g} / \mathrm{mol}$. However, there is a chemical shift $\delta_{\mathrm{H}}=6.85 \mathrm{ppm}$ that belongs to the proton from vinyl group, suggesting the presence of residual monomers in the product.

Similar peaks of residual monomers (signal 15, 16,17) and impurities from the solvent were also found in the ${ }^{1}$ H-NMR spectrum of PNVP-b-PNMA, as shown in Fig.-2(b). These unexpected peaks in the product might happen because of the poor purification process. Nevertheless, it can be seen from the spectrum that the polymerization occurred, and the block copolymer was formed because of the presence of the signals from protons at numbers $4\left(-\mathrm{CH}_{2}-\right), 5(-\mathrm{CHN}-), 9(-\mathrm{CHCO})$ and $13\left(-\mathrm{CH}_{2}-\right)$, which belong only to the backbone of the polymers. Scheme-1 shows the polymerization of PNVP-b-PNMA. PNMA repeating units in PNVP-b-PNMA were expected to reach 25, 50, 75 units. Nevertheless, based on ${ }^{1} \mathrm{H}-\mathrm{NMR}$ spectra calculation $^{19}$, the repeating units of PNVP-b-PNMA were obtained to be 15, 17, 20 units (Table-1). This 
could happen because of the short polymerization time and the possibility of oxygen leak inside the reactor, which caused the ATRP catalyst to be oxidized and the polymerization led to the deactivation of the catalysts. $^{20}$

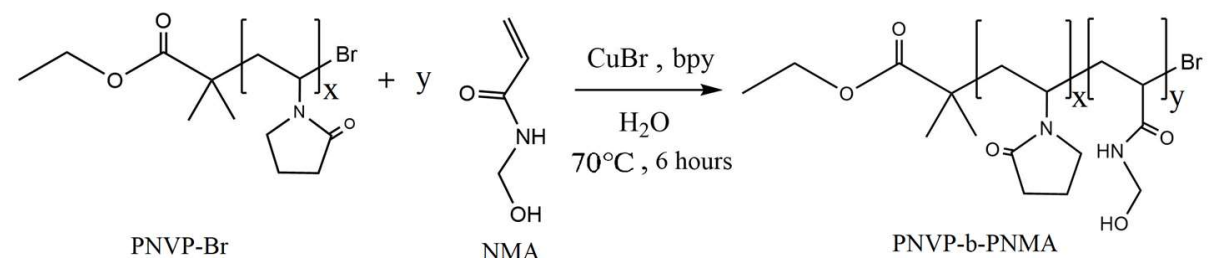

Scheme-1: ATRP polymerization of PNVP-b-PNMA via macroinitiator approach

Table-1: Overview of PNVP-b-PNMAs

\begin{tabular}{c|c|c|c|c}
\hline Polymer & $\begin{array}{c}\text { NMA:PNVP-Br in feed } \\
\text { (mol ratio) }\end{array}$ & \multicolumn{2}{|c|}{$\begin{array}{c}\text { Repeating units } \\
\text { (units) }\end{array}$} & \multirow{2}{*}{$\begin{array}{c}\mathrm{M}_{\mathrm{n}}^{\mathrm{c}} \\
\mathrm{g} / \mathrm{mol} \text { ) }\end{array}$} \\
\cline { 3 - 4 } & & PNVP & PNMA & \\
\hline PNVP $_{50}$-b-PNMA & & \\
\hline PNVP $_{50}-\mathrm{b}-\mathrm{PNMA}_{50}$ & $25: 1$ & 40 & 15 & 5265 \\
\hline PNVP $_{50}-\mathrm{b}-\mathrm{PNMA}_{75}$ & $50: 1$ & 40 & 17 & 5413 \\
\hline
\end{tabular}

${ }^{a} \mathrm{The} \mathrm{CuBr}$ and bpy to initiator mol ratio was $1: 1$ in all cases

${ }^{b}$ Determined by ${ }^{1} \mathrm{H}-\mathrm{NMR}$

${ }^{\mathrm{c}}$ Determined by ${ }^{1} \mathrm{H}-\mathrm{NMR}$ via end group analysis

\section{pH Sensitivity of PNVP-b-PNMA}

Typically, $\mathrm{pH}$-sensitive polymers consist of polyacids or polybases that can form polyelectrolytes (polyanion for polyacids and polycation for polybases). Due to protonation or deprotonation of the chemical structure of polyelectrolytes in acidic or basic solution, their particle size ${ }^{21}$ would change. For instance, the transformation of carboxylic acids into carboxylate anions and vice versa in different $\mathrm{pH}$ results in a reversible change of particle sizes since the carboxylate anions have better interactions with water molecules than carboxylic acid does. Thus, polyelectrolytes with carboxylate anions exist in the form of a coil, while polyelectrolytes with carboxylic acid moieties are present in the form of a globule. In the case of PNMA, since PNMA bearing an amide group, it might undergo hydrolysis in acid or base environment into carboxylic acid ${ }^{22}$ and carboxylate anions ${ }^{23}$, respectively, and thus, the particle sizes change as described earlier.

It was previously reported that hydrogel of $\mathrm{P}(\mathrm{NVP}-\mathrm{co}-\mathrm{NMA})$ has an increasing swelling property at $\mathrm{pH} 3$ 7. ${ }^{6-7,10}$ Therefore, the change of particle sizes was predicted to take place around those $\mathrm{pH}$ ranges. The results from the particle size analyzer for the PNVP-b-PNMA in various pH solutions are presented in Fig.3a, while the illustration of PNVP-b-PNMA pH-sensitivity on the particle sizes is shown in Fig. $-3 b$.

Figure-3a shows that $\mathrm{PNVP}_{50}-\mathrm{b}-\mathrm{PNMA}_{25}$ has an increasing particle size at $\mathrm{pH} 3-7$ with maximum particle sizes occurring at $\mathrm{pH} 7$, then the particle sizes decreased at $\mathrm{pH} 7-12$. The increase of particle sizes of $\mathrm{PNVP}_{50}-\mathrm{b}-\mathrm{PNMA}_{25}$ and $\mathrm{PNVP}_{50}-\mathrm{b}-\mathrm{PNMA}_{50}$ between $\mathrm{pH}$ 3-7 could be explained because the interactions between the polymer chains increased. At neutral $\mathrm{pH}$, the concentration between $\mathrm{H}^{+}$and $\mathrm{OH}^{-}$are equal. Therefore, the interaction between polymer chains would be more dominant than that within a single polymer or with the solvent resulting in an increase in particle sizes. Such behavior also happened in the PNMA homopolymer.

Meanwhile, $\mathrm{PNVP}_{50}-\mathrm{b}-\mathrm{PNMA}_{75}$ had a maximum particle size at $\mathrm{pH} 3$ which could be reasoned because of hydrolysis of the amide group in PNMA to form a carboxylic acid. The -COOH in PNMA block becomes hydrophobic at low $\mathrm{pH}$ since there was no polyanion presence in the polymer chains. As a consequence, the PNMA block prefers to interact with itself to water (hydrophobic effect) and behave as macrosurfactants that can aggregate to form micelles ${ }^{24}$, and thus, the particle sizes became large. In addition, the particle size tended to decrease after $\mathrm{pH} 7$ because of the deprotonation of a carboxylic acid into carboxylate anions that makes both PNVP and PNMA blocks hydrophilic and preferred to interact with water, and thus, the particle sizes became small (Fig.-3b). 
RASĀYAN J. Chem.

Vol. 14 | No. 4 |2671-2676| October- December | 2021

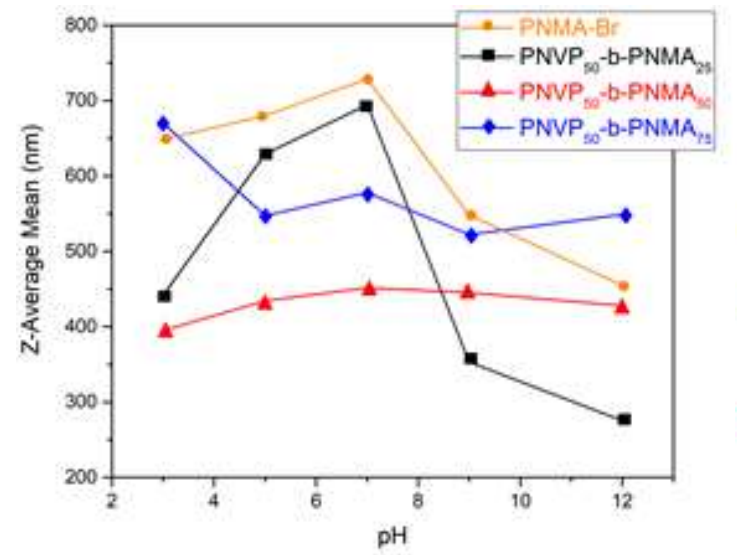

(a)

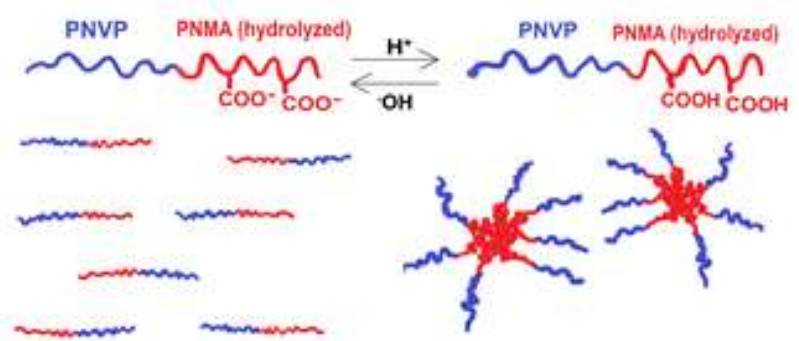

(b)

Fig.-3: (a) The change of particle sizes in various pH; (b) illustration of PNVP-b-PNMA pH-sensitivity

In general, the increasing NMA content in PNVP-b-PNMA promoted larger particle sizes of the block copolymers in acid and base environments. The end group analysis of the ${ }^{1} \mathrm{H}-\mathrm{NMR}$ showed that block copolymers of PNVP-b-PNMA obtained similar repeating units. Nonetheless, the PSA results showed a major difference in the change of particle sizes of PNVP-b-PNMA in various $\mathrm{pH}$. Presumably, this might be due to residual monomers that could influence the change of particle sizes.

\section{CONCLUSION}

PNVP-b-PNMAs were prepared using ATRP via the macroinitiator approach. The existence of functional groups in FT-IR and some signals belonging to PNVP-Br or PNVP-b-PNMA in ${ }^{1} \mathrm{H}-\mathrm{NMR}$ indicated that the polymerization occurred. PNVP-b-PNMAs show responsiveness in different $\mathrm{pH}$ through the change of particle sizes. In general, PNVP-b-PNMA in $\mathrm{pH} 3,5$, and 7 had larger particle sizes $(394.86-694.56 \mathrm{~nm})$ than in $\mathrm{pH} 9$ and $12(275.43-548.70 \mathrm{~nm})$. The more NMA content in block copolymers of PNVP-b-PNMA was, the larger particle sizes could be obtained.

\section{ACKNOWLEDGEMENT}

This research was financially supported by Hibah Penelitian Dasar Unggulan Perguruan Tinggi (PDUPT) Kementerian Riset dan Teknologi/Badan Riset dan Inovasi Nasional, Contract number: NKB-179/UN2.RST/HKP.05.00/2021.

\section{REFERENCES}

1. M. Wei, Y. Gao, X. Li, and M. J. Serpe, Polymer Chemistry, 8(1), 127(2017), https://doi.org/10.1039/C6PY01585A

2. R. Saxena, and S. C. Bhatt, Rasayan Journal of Chemistry, 10(4), 1340(2017), http://doi.org/10.7324/rjc.2017.1041869

3. E. R. Wikantyasning, M. Mutmainnah, Z. Cholisoh, I. Hairunisa, M. F. A. Bakar, and M. Da'I, Rasayan Journal of Chemistry, 12(4), 1857(2019), http://dx.doi.org/10.31788/RJC.2019.1245209

4. Darjito, M. M. Khunur, D. Purwonugroho, M. A. Yuliantari, Z. R. Sari, L. H. A. K. Suryaningrat, and Y. P. Prananto, Rasayan Journal of Chemistry, 12(3), 1485(2019), http://dx.doi.org/10.31788/RJC.2019.1235220

5. D. Kraisiri, N. Chantarasiri, and V. Pimpan, Academic Journal of Science, 1(2), 183(2012)

6. M. Rizky and N. M. Nizardo, in Proceedings of AIP Conference Proceedings, 2374, 040002(2021), https://doi.org/10.1063/5.0058725

7. R. R. Mashudi and N. M. Nizardo, in Proceedings of AIP Conference Proceedings, 2374, 040009(2021), https://doi.org/10.1063/5.0058723

8. M. Teodorescu and M. Bercea, Polymer Plastics Technology and Engineering, 54(9), 923(2015), https://doi.org/10.1080/03602559.2014.979506

9. A. Veeren, A. Bhaw-Luximon, and D. Jhurry, European Polymer Journal, 49(10), 3034(2013), https://doi.org/10.1016/j.eurpolymj.2013.06.020 


\section{RASĀYAN J. Chem.}

Vol. 14 | No. 4 |2671-2676| October- December | 2021

10. O. G. Marambio, G. del C. Pizarro, M. Jeria-Orrel, and K. E. Geckeler, Journal of Applied Polymer Science, 113, 1792(2009), https://doi.org/10.1002/app.29944

11. X. Lu, S. Gong, L. Meng, C. Li, S. Yang, and L. Zhang, Polymer, 48(10), 2835(2007), https://doi.org/10.1016/j.polymer.2007.03.048

12. Z. Fu et al., Journal of Colloid and Interface Science, 394(1), 409(2013), https://doi.org/10.1016/j.jcis.2013.01.010

13. A. Narumi et al., Macromolecules Chemistry and Physics, 210(5), 349(2009), https://doi.org/10.1002/macp.200800509

14. Y. Kotsuchibashi, Y. Kuboshima, K. Yamamoto, and T. Aoyagi, Polymer Chemistry, 46, 6142(2008), https://doi.org/10.1002/pola.22925

15. M. H. Casimiro, S. R. Gomes, G. Rodrigues, J. P. Leal, L. M. Ferreira, Materials, 11(12), 2535(2018), https://doi.org/10.3390/ma11122535

16. J. Zhang, B. Yuan, and H. Ren, In Proceedings of IOP Conference Series for Earth and Enviromental Sciences, 170 (2018), https://doi.org/10.1088/1755-1315/170/3/032043

17. F. Haaf, A. Sanner, and F. Straub, Polymer Journal, 17(1), 143(1985), https://doi.org/10.1295/polymj.17.143

18. Y. Luan, A. Song, G. Xu. Soft Matter, 5(13), 2587 (2009), https://doi.org/10.1039/b900816k

19. J. U. Izunobi, C. L. Higginbotham, Journal of Chemical Education, 8(88), 1098(2011), https://doi.org/10.1021/ed100461v

20. M. Teodorescu and K. Matyjaszewski, Macromolecules, 21(4), 190(2000), https://doi.org/10.1021/ma025883o

21. L. García-Fernández, A. Mora-Boza, and F. Reyes-Ortega, 2019, pH-Responsive Polymers: Properties, Synthesis, and Applications, in: M.R. Aguilar and J.S. Roman, Smart Polymers and Their Applications, Woodhead Publishing, pp.45-86, https://doi.org/10.1016/b978-0-08-102416-4.00003-x

22. Y. Pei, L. Zhao, G. Du, N. Li, K. Xu, and H. Yang, Petroleum, 2(4), 399(2016), https://doi.org/10.1016/j.petlm.2016.08.006

23. J. G. Smith, Organic Chemistry, 3rd Ed., McGraw-Hill, New York, p.855(2011)

24. N. Singh, P.K.S. Yadav, and S.K. Gupta, Rasayan Journal of Chemistry, 13(3), 1644(2020), http://dx.doi.org/10.31788/RJC.2020.1335387

[RJC-6400/2021] 